JIOM Nepal, Volume 41, Number 2, August 2019, page 1-3

\title{
Nephron Sparing Surgery for Small Renal Mass at a University Teaching Hospital: A Six Years Retrospective Review
}

\author{
Bipendra DK Rai, Sujeet Poudyal, Pawan Dhital, Manish Pradhan, Suman Chapagain, Bhoj R Luitel, \\ Pawan R Chalise, Uttam K Sharma, Prem R Gyawali \\ Department of Urology and Kidney Transplant Surgery, Maharajgunj Medical Campus, Tribhuvan University Teaching \\ Hospital, Kathmandu, Nepal
}

\section{Corresponding author:}

Bipendra DK Rai, MBBS, MS

Department of Urology and Kidney Transplant Surgery, Maharajgunj Medical Campus, Tribhuvan University Teaching Hospital, Kathmandu, Nepal

Email: raibipen@yahoo.com

Submitted: Nov 5, 2018

Accepted : Jul 24, 2019

\begin{abstract}
Introduction

Nephron-sparing surgery (NSS) is the standard of care for clinical T1 (cT1), renal mass less than $7 \mathrm{~cm}$, whenever intervention is indicated. It has oncological outcome equivalent to radical nephrectomy in small renal masses and it also minimizes the progression to chronic kidney disease. However, there is paucity of data on outcomes of NSS in Nepalese population.
\end{abstract}

\section{Methods}

A six years retrospective review of medical records of patients undergoing partial nephrectomy from Jan 2012 to Dec 2017 in Department of Urology and Kidney Transplant Surgery at Tribhuvan University Teaching Hospital was done to determine its demographics and outcomes.

\section{Results}

Twenty eight patients underwent nephron sparing surgery for clinical T1 renal masses in the past six years. Complications occurred in three cases. Five of the lesions were benign and 23 malignant on final histology. Clear cell carcinoma was the commonest variant of renal cell cancer. Margin was positive in two cases and both were kept in close surveillance. There was no local recurrence and renal impairment during five to 60 months followup.

\section{Conclusion}

Nephron sparing surgery is a safe procedure with good oncological outcome for clinical T1 renal mass. It prevents unnecessary nephrectomy in benign lesions as well as chronic renal impairment at the same time.

Keywords: Nephron sparing surgery, small renal mass

\section{INTRODUCTION}

$\mathrm{R}$ adical nephrectomy with its minimal complications and good oncological outcome has stood the test of time for the treatment for renal masses. ${ }^{1}$ However, despite a higher complication rate and increased complexity of surgery, partial nephrectomy (PN) has up surged radical nephrectomy for the treatment of selected small renal masses of less than seven $\mathrm{cm} .{ }^{2,3}$ Partial nephrectomy or Nephron sparing surgery (NSS) provides a similar oncological outcome with the advantage of nephron preservation in patients with small renal masses, which is important in patients with diminished renal reserve, solitary kidney or bilateral renal masses. ${ }^{3,4}$
Though incidental and small renal masses are rising in the developed countries, renal masses requiring radical nephrectomy are still common in Nepal. ${ }^{5,6}$ There is very little published data on long term outcomes of NSS in Nepal. Here, we retrospectively reviewed the medical records evaluating the pathology, complications and outcome of the cases that underwent renal preserving surgery over six year period in our institute.

\section{METHODS}

We conducted a retrospective study in the Department of Urology and Kidney Transplant Surgery, Tribhuvan University Teaching Hospital, Kathmandu, Nepal and medical records of all patients undergoing 
NSS from January 2012 to December 2017 were reviewed. Demographic data, lesion characteristics, complications and follow-up outcomes of the patients were analyzed. Tumor Node Metastasis (TNM) staging was done applying the 2017 TNM classification system.

\section{RESULTS}

A total of 28 patients underwent NSS surgery in our institute over a period of six years. The mean age of the patients was $56 \pm 16$ years ranging from $20-90$ years. The male to female ratio was 2.5: 1.

Most of the patients (57\%) were symptomatic, with pain and hematuria in 15 and one patients respectively. Only 12 cases were detected incidentally. Four patients had solitary functioning kidneys and one had renal stone in the ipsilateral pelvis.

Masses were located in the upper or lower pole in 23 patients and remaining five patients had the masses in the interpolar region of the kidneys. The mean size of the lesion was $3.6 \pm 1.7 \mathrm{~cm}$ and was removed with a mean cold ischemia time of $16.9 \pm 7.1$ mins. The important operative outcome of the patients who had undergone NSS is presented in table 1.

Complications were seen in three patients. Two patients who developed fistula had lesion in the interpolar region. The patients with pyelo-cutaneous fistula were successfully managed conservatively with insertion of double $\mathrm{J}$ stent and prolonged retroperitoneal drainage. The patient with surgical site infection required secondary suturing. Hospital stay was longer in these patients.

Majority of the resected lesions (82.1\%) were malignant. Low grade clear cell carcinoma was the most common histopathological finding in the current series. Both patients with positive surgical margin had lesion in the intrahilar region, however as both the lesions were of low grade (Furhman grade I) and hence were kept on close follow-up. On followup of these patients (range 5 -60 months), none of the patients have developed recurrence including patients with positive surgical margin. All the patients including those with functionally solitary kidney had not developed renal failure.

\section{DISCUSSION}

Small renal masses usually present around sixth and seventh decade of life. ${ }^{7}$ But in our study it was more common in fifth decade which is similar to series reported by Agnihotri et al in an Indian and by Shin et al. in a Korean population.,8 In our series, 57\% of the patients were less than 60 years old which is similar to other series reported from Nepal and India. 5,7 It may be a representation of different trend among the Asian population but may be the result of only a small proportion of patient presenting as small renal masses as compared to Western population. In
Table 1. Operative outcomes

\begin{tabular}{lc}
\hline \multicolumn{1}{c}{ Variable } & Number \\
\hline Mean hemoglobin drop & $0.9(0.5-1.6) \mathrm{gm} / \mathrm{dl}$ \\
Transfusion & 0 \\
Median hospital stay (days) & $5(5-14)$ \\
Complications & \\
$\quad$ Pyelocutaneous fistula & 2 \\
$\quad$ Surgical site infection & 1 \\
\hline
\end{tabular}

the West $60 \%$ of the patients present as T1a lesion, whereas only $16 \%$ of our patients fall in the category. ${ }^{9}$ Renal masses were more common among males in our series which is similar to the world literatures..$^{10}$ In the West $48-66 \%$ of small renal masses are detected incidentally. ${ }^{6}$ But in the current series, only onethird of the patients presented with an incidentally detected mass supporting the previously published series from Nepal. ${ }^{11}$

The advantage of NSS is exemplified by the four patients who had functional solitary kidney remaining dialysis free over the study period. The overall complication rate was $12.3 \%$ in our series which is not higher than reported in large series. Although the reported risk of hemorrhage is about $3.1 \%$ we did not have any hemorrhagic complications. ${ }^{12,13}$ It may be the reflection of only a small number of partial nephrectomies being done in our institute. The morbidity just prolonged the duration of hospital stay in our series.

Table 2. Pathological characteristics of the patients

\begin{tabular}{cc}
\hline \multicolumn{1}{c}{ Variable } & Number \\
\hline Histopathology & Total $=28$ \\
Malignant & Sub-total=23 \\
Clear cell RCC & 19 \\
Papillary RCC & 1 \\
Chromophobe RCC & 3 \\
Benign & Sub-total=5 \\
Oncocytoma & 1 \\
Cystic nephroma & 1 \\
Xanthogranulomatous & 2 \\
pyelonephritis & \\
Angiomyolipoma & 1 \\
Furhman grade & Total=19 \\
(clear cell carcinoma) & \\
I & 6 \\
II & 10 \\
III & 3 \\
Stage & Total=23 \\
T1a & 16 \\
T1b & 7 \\
Margin status (malignant lesions) & Total=23 \\
Free & 21 \\
Positive & 2 \\
Lymphovascular invasion & 0 \\
\hline
\end{tabular}


Our series highlights another benefit of partial nephrectomy where there is possibility of a benign pathology. Five (18\%) cases were benign which is similar to those mentioned in literature and hence radical nephrectomy would have been an overtreatment in these cases. ${ }^{14}$ Clear cell renal cell carcinoma is the commonest histology found in patients with small renal masses accounting for 82$88 \%$ of renal masses. ${ }^{15}$ Clear cell renal cell carcinoma was the most common variant comprising of $82.6 \%$ of the resected malignant lesion in the current series. Positive surgical margins can occur in $8 \%$ of cases undergoing nephron sparing surgery. ${ }^{16}$ Two of the patients in our series had a positive surgical margin. There are multiple non surgical and surgical approaches to manage a patient with a positive surgical margin and observation with follow-up is one of the options. It is based on the published reports showing that only patient with high grade tumors have a higher chance of recurrence and there is comparable five year cancer specific and recurrence free survival among margin positive and negative cases. ${ }^{17,18}$ Since our patients with positive surgical margins had low grade (Furhman grade I) disease we kept the patients on follow-up and they have not shown any recurrence for up to three years of followup.

\section{CONCLUSION}

Though our series is small, the study has shown that NSS is a feasible option with good short term and intermediate term outcome in Nepalese patients with small renal masses.

\section{CONFLICT OF INTEREST}

None declared.

\section{REFERENCES}

1. Joudilow FN, Allareddylow $\mathrm{V}$, Kane CJ, Konety BR. Analysis of complications following partial and total nephrectomy for renal cancer in a population based sample. Journal of Urology 2007; 177(5): 1709-1714

2. Yang $G$, Villalta JD, Meng $M V$, Whitson JM. Evolving practice patterns for the management of small renal masses in the USA. BJU International 2012; 110: 11561161.

3. Van Poppel H, Da Pozzo L, Albrecht W, Matveev V, Bono A, Borkowski A et al. A prospective randomized EORTC intergroup phase 3 study comparing the complications of elective nephron-sparing surgery and radical nephrectomy for low-stage renal cell carcinoma. Eur Urol 2007; 51(6): 1606-1615.

4. Nieder AM, Taneja SS. The role of partial nephrectomy for renal cell carcinoma in contemporary practice. Urol Clin North Am 2003; 30(3): 529-542.
5. Sidharth, Luitel BR, Gupta DK, Maskey P, Chalise PR, Sharma UK et al. Pattern of Renal Cell Carcinoma - A Single Center Experience in Nepal. Kathmandu Univ Med J 2011; 35(3): 185-188.

6. Volpe A, Jewett MAS. The Natural History of Small Renal Masses. Nat Clin Pract Urol 2005; 2(8): 384-390.

7. Agnihotri S, Kumar J, Jain M, Kapoor R, Mandhani A. Renal cell carcinoma in India demonstrates early age of onset \& a late stage of presentation. The Indian Journal of Medical Research. 2014;140(5):624-629.

8. Shin SJ, Ko KJ, Kim TS, Ryoo HS, Sung HH, Jeon HG, et al. (2015) Trends in the Use of Nephron-Sparing Surgery over 7 Years: An Analysis Using the R.E.N.A.L. Nephrometry Scoring System. PLOS ONE 10(11): e0141709. https://doi.org/10.1371/journal.pone.0141709

9. Salagierski $M$, Akdogan $B$, Brookman-May $S$,

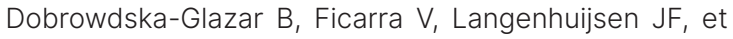
al. What is the contemporary role of radiofrequency ablation in the management of small renal masses? Are small lesions the radiologist's tumors? Eur Urol. 2013;63:493-5

10. Wong MCS, Goggins WB, Yip BHK, Fung FDH, Leung C, Fang $Y$ et al. Incidence and mortality of kidney cancer: temporal patterns and global trends in 39 countries. https://www.nature.com/articles/s41598-017-15922-4 (accessed 29 July 2018).

11. Gupta DK, Luitel BR, Chalise PR, Chapagain S, Subedi P, Thakur DK et al. Nephron Sparing Surgery in a Tertiary Care Center in Nepal- An Initial Experience. J Nepal Health Res Counc 2014; 12(27): 109-11.

12. Mir MC, Derweesh I, Porpiglia F, Zargar $H$, Mottrie A, Autorino R. Partial Nephrectomy Versus Radical Nephrectomy for Clinical T1b and T2 Renal Tumors: A Systematic Review and Meta-analysis of Comparative Studies. Eur Urol 2016; 71: 606-617

13. Larcher A, Fossati N,Tian Z, Boehm K, Meskawi $M$, Valdivieso $R$ et al. Prediction of Complications Following Partial Nephrectomy: Implications for Ablative Techniques Candidates. Eur Urol 2016; 69(): 676-682.

14. Campbell SC, Novick AC, Belldegrun A, Blute ML, Chow GK, Derweesh IH et al. Guideline for management of the clinical T1 renal mass. J Urol 2009; 182(4): 1271-1279.

15. Sun $M$, Abdollah $F$, Bianchi $M$, Trinh $Q$, Jeldres $C$, Tian $Z$, et al. A stage-for-stage and grade-for grade analysis of cancer specific mortality rates in renal cell carcinoma according to age: A competing-risks regression analysis. Eur Urol. 2011; 60:1152-9.

16. Choi JE, You JH, Kim DK, Rha KH, Lee SH. Comparison of perioperative outcomes between robotic and laparoscopic partial nephrectomy: a systematic review and meta-analysis. Eur Urol 2015; 67:891-901.

17. Shah PH, Moreira DM, Okhunov Z, Patel VR, Chopra S, Razmaria AA et al. Positive Surgical Margins Increase Risk of Recurrence after Partial Nephrectomy for High Risk Renal Tumors. Urol Oncol 2017; 35(6): 449-450.

18. Bensalah K1, Pantuck AJ, Rioux-Leclercq N, Thuret R, Montorsi F, Karakiewicz PI et al. Positive surgical margin appears to have negligible impact on survival of renal cell carcinomas treated by nephron-sparing surgery.. Eur Urol 2010; 57(3): 466-471. 